\title{
Magali Carrillo Rocha, 1809: Todos los peligros y esperanzas. Bucaramanga: Universidad Industrial de Santander, 2011.
}

DOI: http://dx.doi.org/10.15648/hc.28.2016.11

A cinco años de haberse conmemorado el Bicentenario nacional, aún quedan algunos ecos que deben ser estudiados. Uno de ellos es la colección publicada por la Universidad Industrial de Santander, la cual está integrada por numerosos textos que ofrecen renovadas tesis y problemas sobre el período fundacional. De manera especial, esta colección difunde conjuntos de documentos inéditos que contribuyen al esclarecimiento de un proceso que la historiografía colombiana ha empezado a reevaluar.

Este es el caso de la compilación que ofrece Magali Carrillo Rocha. Las cuarenta y siete piezas distribuidas en dos volúmenes, y ordenadas cronológicamente, son un panorama que permite al lector formarse una imagen de las controversias y escollos que empezaron a enfrentar los neogranadinos de cara a la crisis monárquica durante 1809. La compilación tiene algunos documentos ya publicados, pero su mayoría son inéditos.

La introducción ofrece al lector un fuerte argumento para explicar la necesidad de aprehender con suficiencia el año 1809. Para la autora, las ambigüedades y los dilemas que los neogranadinos deben afrontar de cara al poder en ese año, son esenciales para entender la crisis de la monarquía y la posterior formación de una nueva entidad política. Tres son los grandes núcleos en los cuales Carrillo Rocha agrupa las divergencias y tensiones que afloraron en distintos territorios del Virreinato de la Nueva Granada durante el año en cuestión. En primer lugar está la sinuosa ambigüedad entre una actitud de lealtad al Monarca y la simultánea erosión del poder real. Un ejemplo de lo anterior se aprecia al observar cómo en el Chocó, Santa Fe o Mompós la figura del Virrey Amar y Borbón fue objeto de múltiples cuestionamientos agrupados bajo la idea de ser un afrancesado 
agente de Godoy. Las diatribas contra la primera autoridad del Virreinato se hacían en nombre del Rey y el interés de proteger sus dominios como a sus súbditos de caer en manos de Napoleón; pero sin duda, este sendero condujo a debilitar su autoridad como representante del Rey. En segundo lugar, se encuentran las tensiones que emergieron al contemplarse entre los notables la posibilidad de instalar en Santa Fe una Junta de Gobierno similar a las establecidas en la Península. El tema escaló ante la formación en Quito de un proyecto con estas características. La discusión frente a este acontecimiento al sur del territorio virreinal, así como el debate sobre si seguir o no el mismo camino, dejó al descubierto los problemas relativos al poder y al ejercicio de gobierno. Finalmente, se encuentra la separación entre americanos y peninsulares, lo que, en otras palabras, es la formación de un 'nosotros' ante los 'ellos'. Esta separación está marcada por la disputa en torno a la mínima representación otorgada por la Junta Central Suprema en comparación con el número de representantes destinados para los peninsulares. Estos argumentos, como la tesis expuesta por Carrillo Rocha sobre la importancia de 1809, nos permite entender que 1810 no es, sin duda alguna, el punto de partida de una experiencia política, sino más bien una parte integral del proceso revolucionario en el año eje de estos libros, parece encubar los ejes sobre los cuales se articuló la urdimbre política que irá dando lugar a la formación de una entidad política republicana desgajada de una de carácter monárquico.

Los registros que documentan los tres núcleos expuestos, se encuentran dentro del conjunto de piezas que integran los dos tomos de la obra. En ellos, el investigador o el osado lector movido por simple curiosidad podrá hallar cartas personales, actas de cuerpos de gobierno, expedientes judiciales, anónimos e impresos, comunicaciones entre autoridades, representaciones y una pieza de oratoria sagrada que le permitirá aproximarse a las experiencias que colmaron a los neogranadinos en 1809 de "todos los peligros y esperanzas".

\section{David Fernando Prado Valencia}

Historiador egresado de la Universidad del Cauca Estudiante de la Maestría en Historia Universidad del Valle Miembro del Grupo de Investigación Estado Nación: Instituciones y Organizaciones davidprado05@hotmail.com 